Editorial

\title{
Fiber-Reinforced Cement Composites: Mechanical Properties and Structural Implications 2019
}

\author{
Doo-Yeol Yoo (iD, ${ }^{1}$ Nemkumar Banthia ${ }^{(D)},{ }^{2}$ Kazunori Fujikake, ${ }^{3}$ Young Hoon Kim $\left(\mathbb{D},{ }^{4}\right.$ \\ and Rishi Gupta ${ }^{5}$ \\ ${ }^{1}$ Department of Architectural Engineering, Hanyang University, 222 Wangsimni-ro, Seongdong-gu, Seoul 04763, \\ Republic of Korea \\ ${ }^{2}$ Department of Civil Engineering, The University of British Columbia, 6250 Applied Science Lane, Vancouver, \\ BC V6T 1Z4, Canada \\ ${ }^{3}$ Department of Civil and Environmental Engineering, National Defense Academy, Yokosuka 239 8686, Japan \\ ${ }^{4}$ Department of Civil and Environmental Engineering, University of Louisville, Louisville, KY 40292, USA \\ ${ }^{5}$ Department of Civil Engineering, University of Victoria, 3800 Finnerty Road, Victoria, BC V8W 2Y2, Canada
}

Correspondence should be addressed to Doo-Yeol Yoo; dyyoo@hanyang.ac.kr

Received 18 July 2019; Accepted 18 July 2019; Published 4 August 2019

Copyright (C) 2019 Doo-Yeol Yoo et al. This is an open access article distributed under the Creative Commons Attribution License, which permits unrestricted use, distribution, and reproduction in any medium, provided the original work is properly cited.

In order to overcome inherent brittleness of concrete, numerous studies on the development of high ductility fiberreinforced cement composites have been performed thus far. Several different types of fiber-reinforced cement composites with metallic, polymer, carbon, glass, nylon, and waste tire fibers have been successfully developed and effectively applied for building structures due to their benefits of limiting crack propagation and widening from fiber bridging. Highperformance fiber-reinforced cement composites showing strain- or deflection-hardening behavior with multiple microcracks were recently developed, and various relevant studies are actively underway.

This special issue gives a comprehensive overview on fiber-reinforced cement composites, including aspects related to material behavior, strengthening performance, numerical simulation and modeling, and structural implication under various loading conditions (i.e., static, impact, blast, fire, fatigue, etc.). The selection of papers in this special issue was very rigorous.

A number of studies developed a new type of fiberreinforced cement composites and evaluated their mechanical properties. K. Patel et al. studied to practically use recycled glass fibers as a reinforcement for concrete recovered from industrial GFRP-acrylic waste. The maximum enhancement of $22 \%$ was achieved for $0.3 \%$ (by volume) of recycled glass fibers compared to the control concrete sample under the compressive loads, regardless of curing regime, and also the tensile samples having 0.3 vol.\% recycled glass fibers exhibited the maximum tensile strength of $3.46 \mathrm{MPa}$, which is higher than that $(2.48 \mathrm{MPa})$ of control sample. Z. Yao et al. evaluated several mechanical properties of the macro polypropylene (PP) fiber-reinforced concrete, including the flexural and tensile strengths, fracture toughness, and fracture energy. They reported that the inclusion of macro PP fibers is effective in enhancing the strength and energy absorption capacity of plain concrete. At the fiber content of $1 \%$ or $1.5 \%, 29.3 \%$ and $21.4 \%$ higher flexural and tensile strengths were obtained as compared to those of plain concrete, and the fracture energy was also improved with increasing the fiber content. S. Karthiyaini et al. successfully predicted the mechanical strength of fiberreinforced cement composites using multiple regression analysis (MRA) and artificial neural network (ANN). They effectively predicted the compressive strength through ANN model with a coefficient of determination $\left(R^{2}\right)$ of 0.93 , while the split tensile and flexural strengths were well simulated by using the MRA model. L. Wang et al. studied the effectiveness of calcium carbonate $\left(\mathrm{CaCO}_{3}\right)$ whisker and fly ash on the mechanical properties of cement mortar under high temperatures and reported that the hybrid use of $\mathrm{CaCO}_{3}$ 
whisker and fly ash possess preferable high-temperature resistance capacity due to the filler and crack bridging effect of the whisker and accelerated pozzolanic reaction of fly ash. $\mathrm{X}$.-Y. Wang suggested an integrated hydration-strength model for cement-limestone-metakaolin ternary blends. Based on parameter analysis, the synergetic effect on strength development was examined and he suggested optimal combinations of cement-limestone-metakaolin ternary blends. From the early age to later age, the optimum combination of ternary blends shift from high limestone-low metakaolin to low limestone-high metakaolin.

The studies related to the electrical properties on the fiber-reinforced cement composites have been conducted by C. Liu et al. and J. Zheng et al. C. Liu et al. evaluated the selfsensing capability of engineered cementitious composites (ECCs) including multiwalled carbon nanotubes (CNTs) and reported that the percolation threshold value is around $0.3 \%$ by weight and ECCs containing CNTs show good selfsensing ability under flexural loading conditions. The amounts of CNTs significantly affected the self-sensing capacity, and with the increased CNT contents, the amplitude of fractional change in resistivity was reduced. J. Zheng et al. presented a novel coupling electromechanical cellbased smoothed finite element method to accurately simulate the dynamic response of piezoelectric composite material (PCM) structures and noted that it is a robust tool for analyzing the mechanical properties of PCM structures due to its higher accuracy and reliability than the conventional finite element method.

Several researchers have investigated the implications of fiber-reinforced cement composites on the structural elements. I.-H. Yang et al. studied the flexural behavior of highperformance fiber-reinforced concrete beams and predicted their tensile strengths by fitting the moment-curvature curves based on sectional analysis. They reported that flexural strength increased with the steel fiber content and the tensile strength obtained from the material test was greatly different from that calculated from the structural beam test results. The calculated tensile strengths were 23.7-60.7\% lower than those obtained from the material test. In addition, the tensile strength increased with the compressive strength. S.-H. Kim et al. experimentally evaluated the long-term ring deflection of the GFRP mortar pipe and noted that reduced stiffness leads to excessive deflections under long-term pressure. Based on the field test results of the buried GFRP pipes for 664 days, it was verified that the long-term deflection was less than $5 \%$ pipe deflection, suggested by the existing specifications, i.e., ASTM D5365 and AWWA M45. So, the safety of the buried GFRP pipe was verified by the field tests. I. Iskhakov and Y. Ribakov studied the effect of steel fibers to solve the brittle behavior of highstrength concrete and to enhance its elastic-plastic deformation. The applied steel fibers proved to be high efficiency and led to ductile behavior of compressed highstrength concrete elements along with the desired effect at long-term loading. In addition, there was an obvious dependence of transverse deformation on the longitudinal behavior at the ultimate limit state. Lastly, $\mathrm{H}$. Ju et al. estimated the minimum torsional reinforcement of reinforced concrete (RC) and steel fiber-reinforced concrete (SFRC) beams. They reported that the addition of steel fibers improves the crack control of $\mathrm{RC}$ beams at the same reinforcement ratio and the higher amount of torsional reinforcement is required to ensure the reserved strength when the compressive strength of concrete becomes higher. Their proposed prediction model also well evaluated the torsional failure mode of the RC and SFRC beams according to the reserved strength ratio.

Guest editors hope that readers can obtain useful information and discover some recent research trends regarding the fiber-reinforced cement composites. They also wish that their academic curiosities are able to be satisfied from the valuable research results in this special issue. This publication considers a wide range of disciplines, including civil, architectural, and construction engineering, and may appeal to the engineers and scientists in the field.

\section{Conflicts of Interest}

The editors declare that they have no conflicts of interest regarding the publication of this special issue.

Doo-Yeol Yoo Nemkumar Banthia Kazunori Fujikake Young Hoon Kim Rishi Gupta 


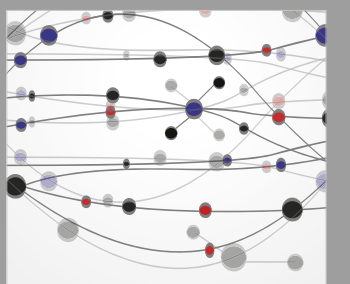

The Scientific World Journal
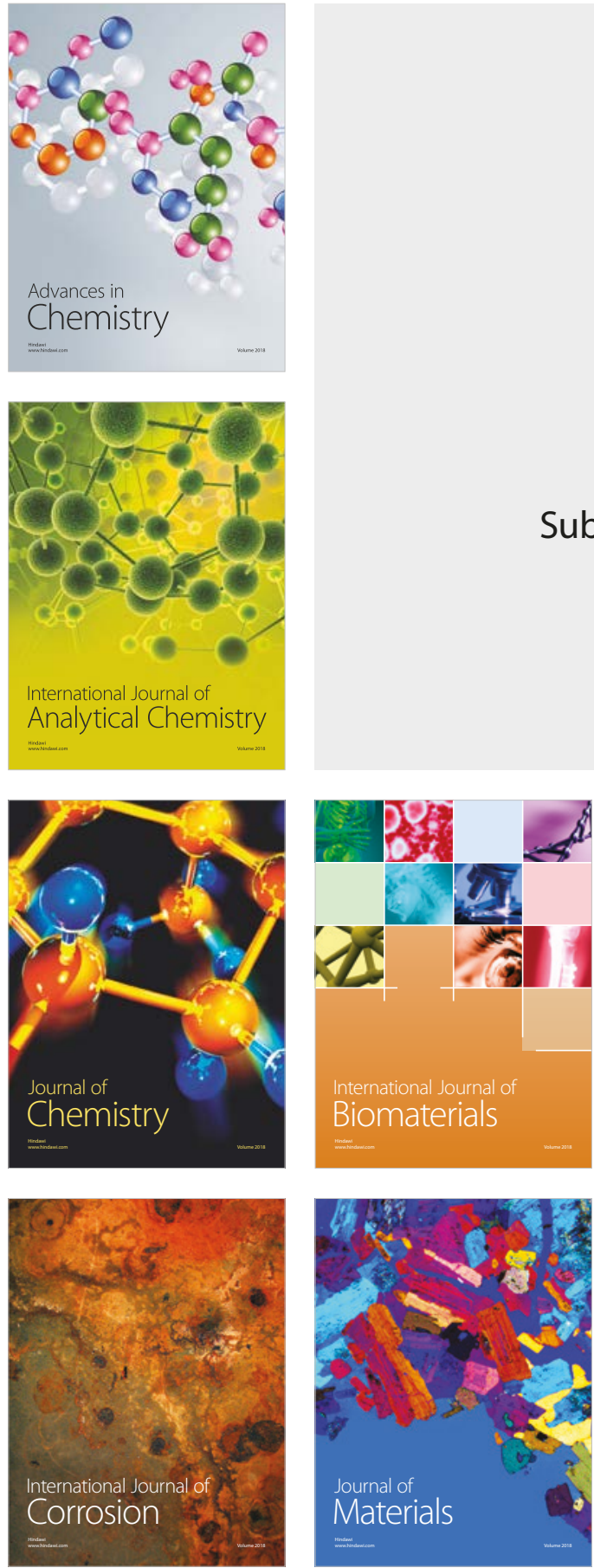

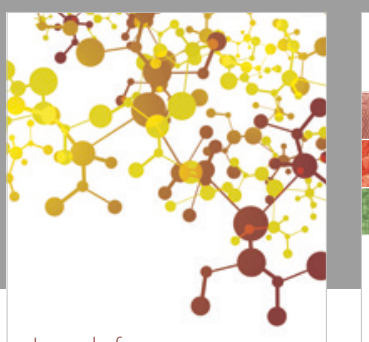

Journal of

Applied Chemistry
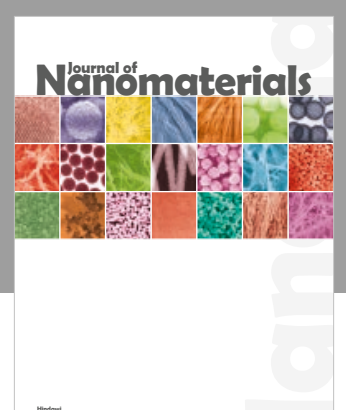

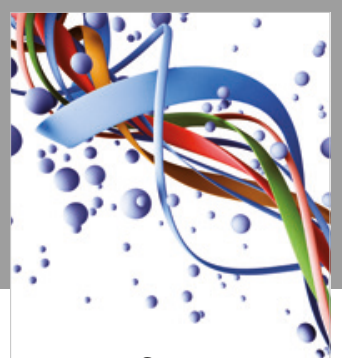

Scientifica

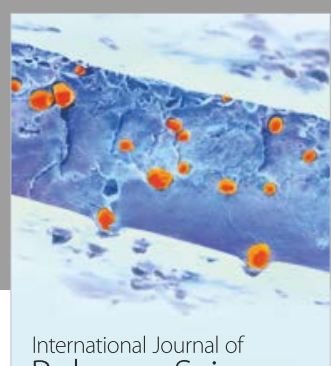

Polymer Science

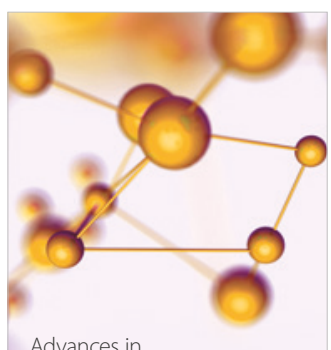

Physical Chemistry
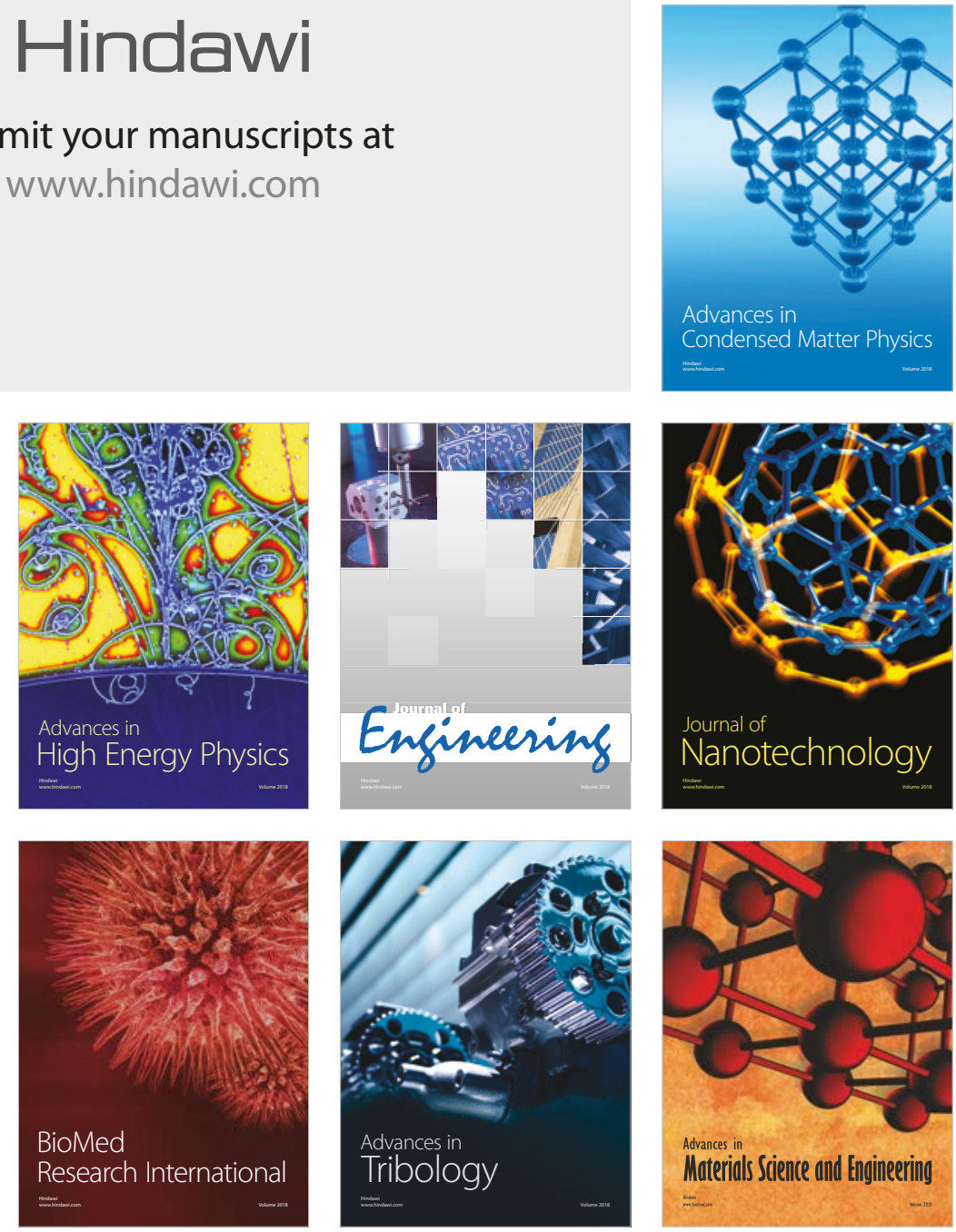